Article

\title{
Activin B Stimulates Mouse Vibrissae Growth and Regulates Cell Proliferation and Cell Cycle Progression of Hair Matrix Cells through ERK Signaling
}

\author{
Pei Tang ${ }^{1, \dagger}{ }^{\dagger}$ Xueer Wang ${ }^{1,+}{ }^{+}$Min Zhang ${ }^{1}$, Simin Huang ${ }^{1}$, Chuxi Lin ${ }^{1}$, Fang Yan ${ }^{1}$, Ying Deng ${ }^{1}$, \\ Lu Zhang ${ }^{2, *(1)}$ and Lin Zhang ${ }^{1, *}$ \\ 1 Guangdong Provincial Key Laboratory of Tissue Construction and Detection, School of Basic Medical \\ Sciences, Southern Medical University, Guangzhou 510515, China; tangpei29@126.com (P.T.); \\ wyy85123@126.com (X.W.); zhangmin507@126.com (M.Z.); huangsimin2006@126.com (S.H.); \\ 18402017785@163.com (C.L.); yanfang@smu.edu.cn (F.Y.); haruno_sakuring@163.com (Y.D.) \\ 2 Guangdong Provincial Key Laboratory of Proteomics, Key Laboratory of Mental Health of the Ministry of \\ Education, School of Basic Medical Sciences, Southern Medical University, Guangzhou 510515, China \\ * Correspondence: zlilyzh@126.com (L.Z.); zlulu70@126.com (L.Z.); \\ Tel.: +86-020-6164-8205 (L.Z.); +86-020-6164-8726 (L.Z.) \\ + These authors contributed equally to this work.
}

Received: 24 December 2018; Accepted: 9 February 2019; Published: 15 February 2019

\begin{abstract}
Activins and their receptors play important roles in the control of hair follicle morphogenesis, but their role in vibrissae follicle growth remains unclear. To investigate the effect of Activin B on vibrissae follicles, the anagen induction assay and an in vitro vibrissae culture system were constructed. Hematoxylin and eosin staining were performed to determine the hair cycle stages. The 5-ethynyl-2'-deoxyuridine (EdU) and Cell Counting Kit-8 (CCK-8) assays were used to examine the cell proliferation. Flow cytometry was used to detect the cell cycle phase. Inhibitors and Western blot analysis were used to investigate the signaling pathway induced by Activin $B$. As a result, we found that the vibrissae follicle growth was accelerated by $10 \mathrm{ng} / \mathrm{mL}$ Activin $B$ in the anagen induction assay and in an organ culture model. $10 \mathrm{ng} / \mathrm{mL}$ Activin B promoted hair matrix cell proliferation in vivo and in vitro. Moreover, Activin B modulates hair matrix cell growth through the ERK-Elk1 signaling pathway, and Activin B accelerates hair matrix cell transition from the G1/G0 phase to the S phase through the ERK-Cyclin D1 signaling pathway. Taken together, these results demonstrated that Activin B may promote mouse vibrissae growth by stimulating hair matrix cell proliferation and cell cycle progression through ERK signaling.
\end{abstract}

Keywords: activin; vibrissae; hair matrix cell; cell proliferation; ERK

\section{Introduction}

Hair has a wide range of functions including thermoregulation, sensory activity, and social interactions in mammals [1]. Mice display at least eight major hair types [1]. Vibrissae is a kind of hair, which is located on both sides of the nasal cavity and serves as a tactile sensory organ [2]. It has been extensively used in hair research as it is large in size and is free from hormonal influences [3].

The hair follicle (HF) is a skin appendage with a complex structure composed of hair bulbs, outer root sheaths (ORS), inner root sheaths (IRS), and the hair matrix [4].The HF undergoes life-long cyclic transformations between telogen (rest), anagen (growth), and catagen (regression) phases [5]. Every phase in HF cycling is stringently regulated by a variety of growth factors [6]. Activins are 
members of the transforming growth factor (TGF)- $\beta$ superfamily [7]. Activin $A(\beta A \beta A)$ and Activin $\mathrm{B}(\beta \mathrm{B} \beta \mathrm{B})$ are the most common types expressed in various tissues [8]. The biological activities of activins are mediated by type I and type II receptors [9]. Some studies have shown that activins and their receptors play important roles in the control of HF morphogenesis and cycling [10]. Activin $\beta A$ and its receptors are widely expressed in HFs [11]. Matzuk and colleagues generated Activin subunit $\beta$ A knockout mice and found that the vibrissae follicles of the mutants showed delayed maturation [12]. Human dermal papilla (DP) spheres with Activin A knockdown show severely impaired HF neogenesis [13]. In our previous study, we found that Activin B can promote mouse pelage HF initiation and development [14]. In a further study, we showed that Activin B could promote HF regeneration after skin wound healing [15]. However, considering the substantial anatomical, biological, and regulatory differences between different types of HFs [16], the role of Activin B in the regulation of vibrissae follicle regeneration is still not clear.

Hair matrix cells reside in the hair bulb [17]. Their proliferation is an important event for hair growth [18]. Some factors which suppress hair matrix cell proliferation can induce an imbalance of HF cycles, resulting in hair loss [19,20]. Nakamura et al. demonstrated that Activin B receptors are expressed in the hair matrix position [10]. However, the role of Activin B in hair matrix cell proliferation and its subsequent signaling pathway have not been reported.

The signaling mechanisms of Activin include Smad-dependent and Smad-independent pathways [21]. Some studies have demonstrated that activin activates mitogen-activated protein kinase (MAPK) pathways [22,23]. MAPKs, comprising JNK, P38, and ERK, are considered to play crucial roles in HF morphogenesis and regeneration [24]. The JNK signaling pathway has been reported to be involved in the apoptosis of HF cells in TGF- $\beta$ induced premature catagen phase [25]. Epidermal growth factor (EGF) and its receptor were also shown to promote anagen phase via the ERK pathway [26].

In the present study, firstly, we investigated the function of Activin B in mouse vibrissae follicle growth by an anagen induction assay and an in vitro vibrissae culture system. Secondly, we assessed the effect of Activin B on the proliferation of hair matrix cells in vivo and in vitro. Thirdly, we investigated the regulation of the MAPK signaling pathway in hair matrix cell proliferation induced by Activin B. Lastly, we explored the role of Activin B in hair matrix cell cycle progression and the relative signaling in this process. Investigating the role and mechanisms of Activin B in hair growth may help to explore the new targets and theoretical options for hair regeneration.

\section{Results}

\section{1. $10 \mathrm{ng} / \mathrm{mL}$ Activin B Accelerated Vibrissae Follicle Growth}

To determine whether Activin B stimulates vibrissae follicle regeneration in vivo, depilation was used to induce vibrissae follicles into a homogeneous anagen stage. We smeared $1 \mathrm{~mL}$ of $10 \mathrm{ng} / \mathrm{mL}$ Activin B or PBS on the vibrissae skin three times a day for 20 days, and observed the color of the vibrissae skin and the hair present every day (Figure 1A). After 10 days of depilation, vibrissae skin in the Activin B-treated mice turned black, and hair shafts emerged through the epidermis. In contrast, the vibrissae skin in the PBS group were gray at 10 days and turned to black at 15 days after depilation (Figure 1A). Owing to the strict coupling of follicular melanogenesis and HF cycling, the change in skin pigmentation is a characteristic of anagen development [27-29]. 
A

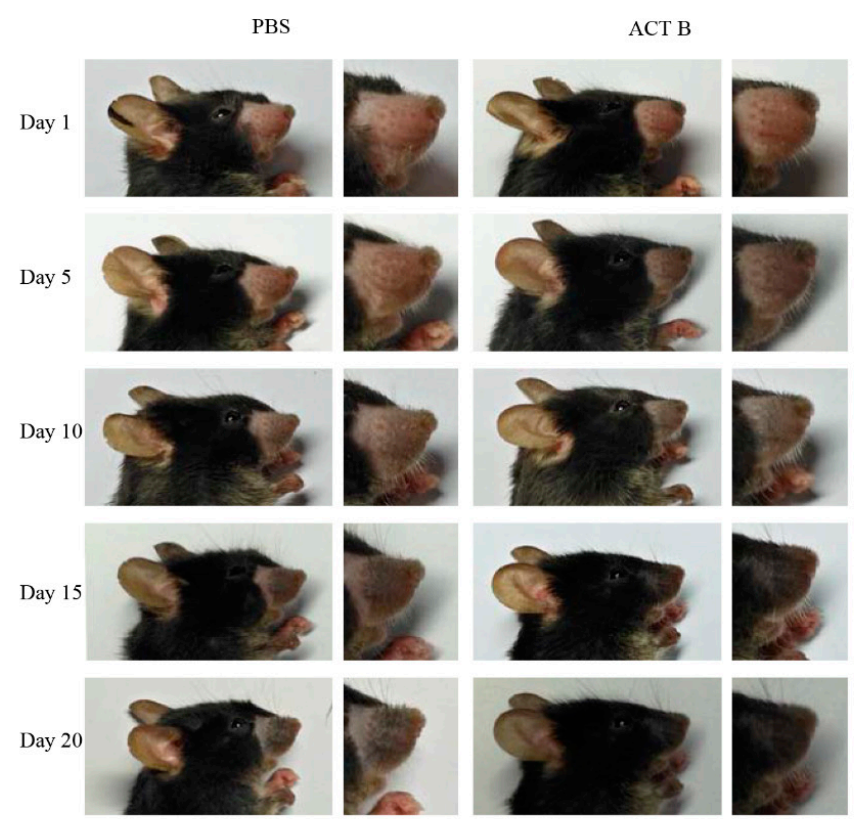

D

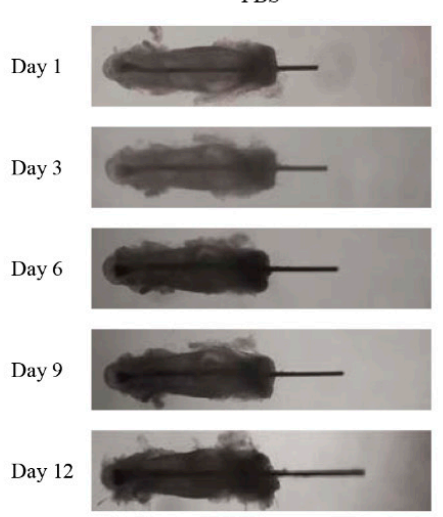

B

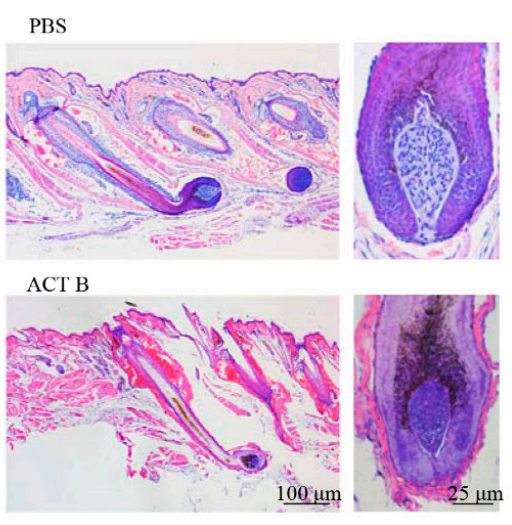

C

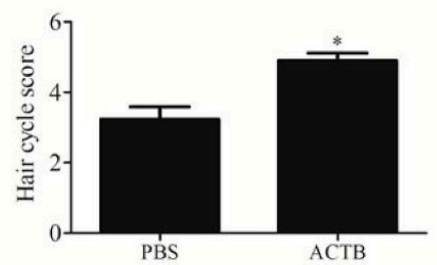

E

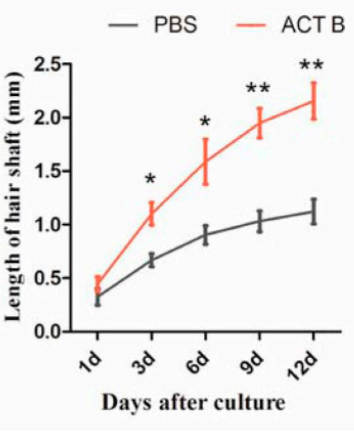

Figure 1. Activin B accelerated vibrissae follicle growth. (A) Gross images of mouse vibrissae treated with $10 \mathrm{ng} / \mathrm{mL}$ Activin B or phosphate buffer solution (PBS) for 1, 5, 10, 15, and 20 days in depilation-induced models. (B) Representative hematoxylin and eosin (H\&E) staining images of vibrissae follicles at 10 days after treatment with PBS or $10 \mathrm{ng} / \mathrm{mL}$ Activin (ACT) B. (C) Hair cycle score for the anagen hair follicles in the PBS and ACT B groups 10 days after depilation, and twenty vibrissae follicles were collected from five mice in each group for quantitative evaluation. (D) Representative pictures of vibrissae cultured with or without $10 \mathrm{ng} / \mathrm{mL}$ Activin B in an in vitro vibrissae culture system. Pictures were taken on 1, 3, 6, 9, and 12 days after culture. (E) Growth curve of the vibrissae shafts over time in the two groups. ${ }^{*} p<0.05 ;{ }^{* *} p<0.01$, compared with the PBS group. Three independent experiments were conducted per data point. All error bars indicate SEM.

We then compared the hair cycle stages of vibrissae follicle in the two groups at 5 days and 10 days after depilation by morphological criteria using hematoxylin and eosin (H\&E) staining, as described previously [30]. At 5 days after depilation, the vibrissae growth in the Activin B group was accelerated, with tips of the IRSs present and a larger DP than the PBS group (Figure S1). At 10 days after depilation, the vibrissae follicles extended into the dermis in the two groups. The hair shaft and IRS reached the hair canal in the Activin B-treated group (Figure 1B). Further, the bulb was enlarged, and the dermal papilla were narrowed in the Activin B group (Figure 1B). All these results suggest that vibrissae follicle treatment with Activin B causes them to enter anagen Stage 5. However, the vibrissae follicles 
in the PBS group were mostly in anagen Stage 3, with the characteristics that the DP is still of loose consistency and not fully surrounded by hair matrix cells (Figure 1B). The quantitative evaluation of hair follicles showed that the average anagen stages of hair follicles in the $10 \mathrm{ng} / \mathrm{mL}$ Activin B group were Stage $5.0 \pm 0.21$, significantly higher than those in the PBS groups with Stage $3.1 \pm 0.35$ (Figure 1C). Taken together, these results suggest that $10 \mathrm{ng} / \mathrm{mL}$ Activin B promotes vibrissae growth in vivo.

\section{2. $10 \mathrm{ng} / \mathrm{mL}$ Activin B Promoted Vibrissae Hair Shaft Elongation in an Organ Culture Model}

We next used an organ culture model to examine the effect of Activin B on the regulation of vibrissae follicle hair growth. In the gross images, the length of vibrissae in the Activin $B$ group was longer than that in the PBS group (Figure 1D). The growth rate of the vibrissae hair shaft was approximately $0.12 \pm 0.13 \mathrm{~mm} /$ day in the Activin B group but only $0.07 \pm 0.06 \mathrm{~mm} /$ day in the PBS group (Figure 1E). These data also show that Activin B could promote vibrissae growth.

\subsection{Activin B Enhanced the Proliferation of Hair Matrix Cells In Vivo and In Vitro}

Hair matrix cell proliferation is required for HF formation [18]. We then assessed the effect of Activin B on hair matrix cell proliferation. The number of EdU-positive cells in the hair matrix was markedly increased in the Activin B group compared to that in PBS group at 10 days after treatment (Figure 2A,B), suggesting that Activin B promotes hair matrix cell proliferation in vivo.

We next examined the effect of Activin $B$ on the proliferation of hair matrix cells in vitro by CCK-8 and EdU assays. The CCK-8 cell growth assay showed that in the range of $5 \mathrm{ng} / \mathrm{mL}$ to $20 \mathrm{ng} / \mathrm{mL}$, Activin B enhanced the proliferation rate of hair matrix cells, whereas at the concentrations of $80 \mathrm{ng} / \mathrm{mL}$ and $160 \mathrm{ng} / \mathrm{mL}$, Activin B inhibited the proliferation of hair matrix cells (Figure 2C). Among the concentrations we tested, $10 \mathrm{ng} / \mathrm{mL}$ Activin B was most effective in promoting human hair germinal matrix cell (HHGMC) proliferation (Figure 2C). Consistent with this, the percentage of EdU-positive cells in the Activin B group $(10 \mathrm{ng} / \mathrm{mL})$ was much higher than that in the PBS group (Figure 2D,E).

The results of the in vivo and in vitro experiments indicate that $10 \mathrm{ng} / \mathrm{mL}$ Activin B enhances the proliferation of hair matrix cells.

\subsection{Activin B Modulated the Proliferation of Hair Matrix Cells Through the ERK-Elk1 Signaling Pathway}

To examine whether the MAPK signaling pathway is involved in Activin B-induced hair matrix cell proliferation, we determined the phosphorylation status of ERK, JNK, and P38 in HHGMCs treated with Activin B. We found that the phosphorylated levels of ERK, JNK, and P38 were all obviously enhanced by Activin B. The level of ERK phosphorylation peaked at $15 \mathrm{~min}$, and returned to the basal level at $4 \mathrm{~h}$ after incubation with Activin B (Figure 3A,B). The level of JNK phosphorylation was activated at $15 \mathrm{~min}$ and at its peak at $2 \mathrm{~h}$ (Figure 3C,D). The expression of phosphorylated P38 was significantly increased after $15 \mathrm{~min}$ of treatment and reached its peak at $30 \mathrm{~min}$ (Figure 3E,F). 
A
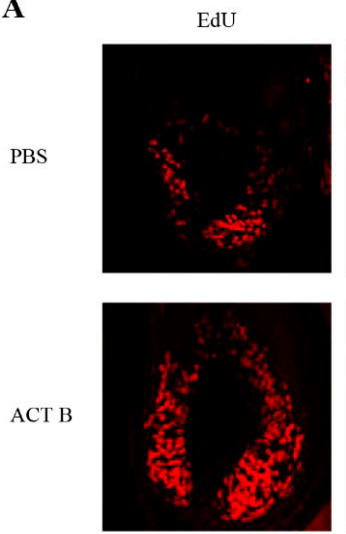

C

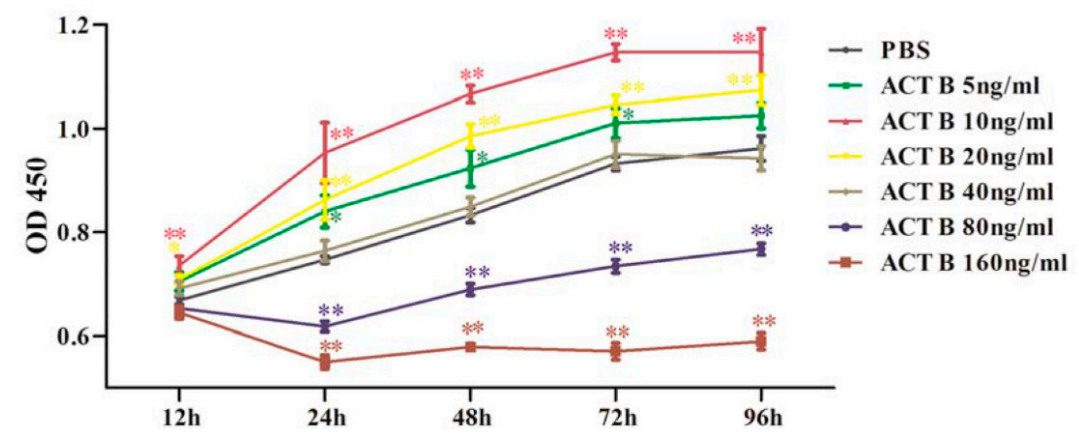

D
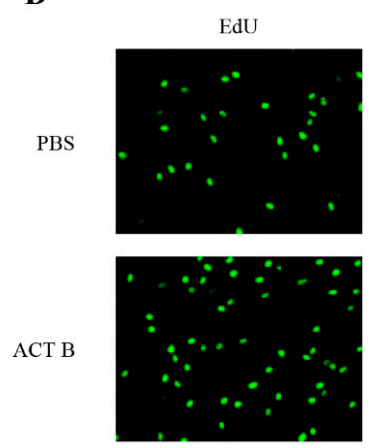

Hochest
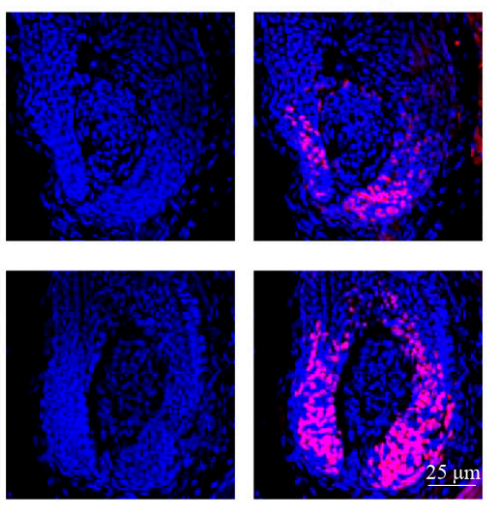

B

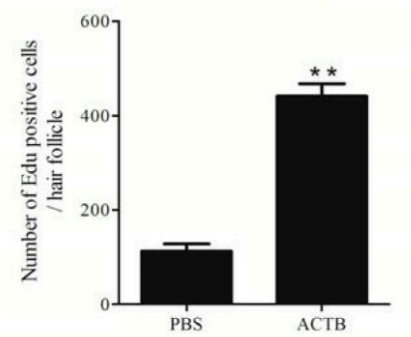

E

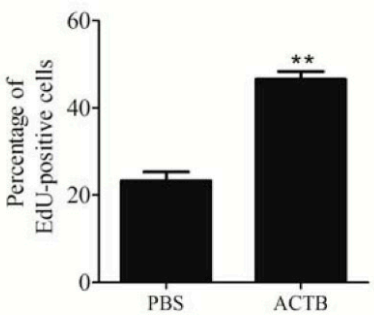

Figure 2. Activin B enhanced the proliferation of hair matrix cells in vivo and in vitro. (A) Representative images of EdU staining (red fluorescence) of vibrissae follicles treated with PBS or $10 \mathrm{ng} / \mathrm{mL}$ Activin B at 10 days after treatment. Nuclei were counterstained with Hoechst 33342 (blue fluorescence). (B) Ten vibrissae follicles per group were collected from five mice in each group and the number of EdU-positive cells in the two groups was counted. (C) Human hair germinal matrix cells (HHGMCs) were treated with Activin B at the concentration of 5, 10, 20, 40, 80, or $160 \mathrm{ng} / \mathrm{mL}$. The CCK-8 assay was performed at 12, 24, 48, 72, and $96 \mathrm{~h}$ after treatment. (D) HHGMCs treated with $10 \mathrm{ng} / \mathrm{mL}$ Activin B or PBS were subjected to EdU assay (green fluorescence). Nuclei were counterstained with Hoechst 33342 (blue fluorescence). (E) The number of positive cells was counted manually in ten fields-of-view randomly selected from each well. The percentages of positive cells were calculated. ${ }^{*} p<0.05 ;{ }^{* *} p<0.01$, compared with the PBS group. Three independent experiments were conducted per data point. All error bars indicate SEM. 
A

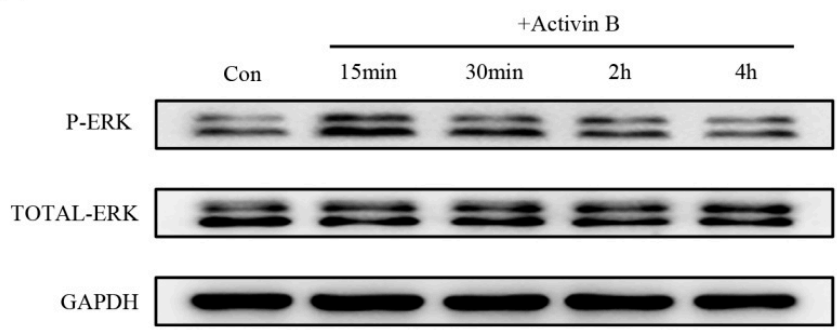

C

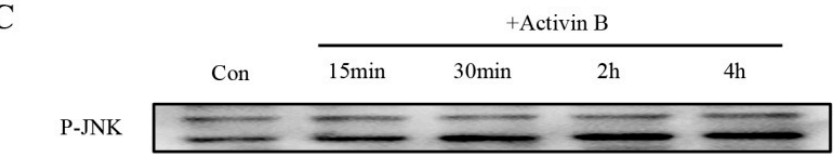

TOTAL-JNK

GAPDH
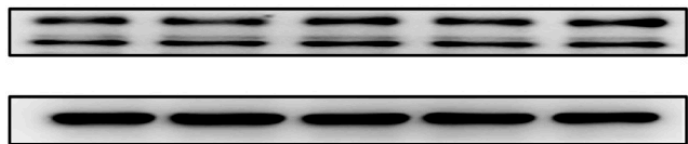

$\mathbf{E}$

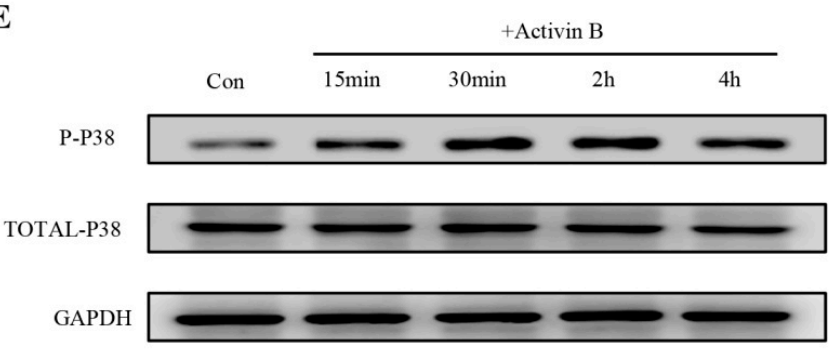

B

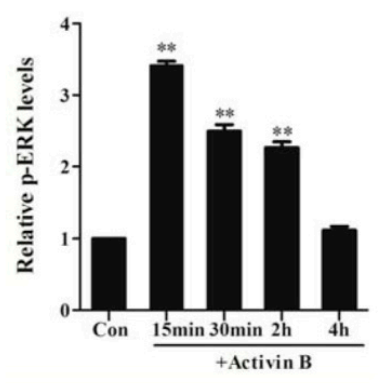

D

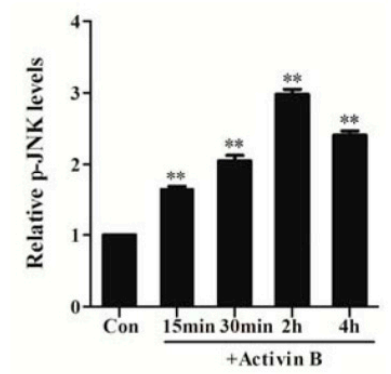

$\mathbf{F}$

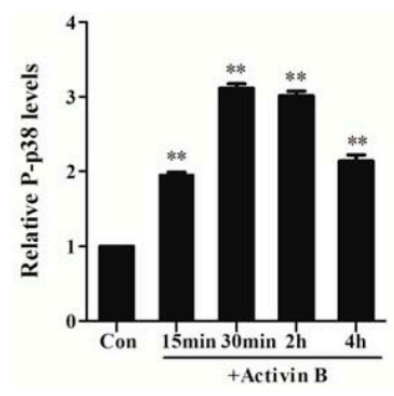

Figure 3. Activin B stimulated JNK, ERK, and P38 phosphorylation in hair matrix cells. (A,B) The plot and the relative quantification of the expression of phosphorylation of ERK in HHGMCs treated with $10 \mathrm{ng} / \mathrm{mL}$ Activin B for $15 \mathrm{~min}, 30 \mathrm{~min}, 2 \mathrm{~h}$, and $4 \mathrm{~h}$. (C,D) The plot and the relative quantification of the expression of phosphorylation of JNK in cells treated with $10 \mathrm{ng} / \mathrm{mL}$ Activin B for different times. (E,F) The plot and the relative quantification of the expression of phosphorylation of P38 in cells treated with $10 \mathrm{ng} / \mathrm{mL}$ Activin B for different times. ${ }^{*} p<0.05$; ${ }^{* *} p<0.01$, compared with the PBS group. Three independent experiments were conducted per data point. All error bars indicate SEM.

To determine whether ERK, JNK, and P38 signaling were involved in HHGMC proliferation induced by Activin B, JNK inhibitor SP600125, ERK inhibitor SCH772984, and P38 inhibitor SB202190 were used to pretreat the HHGMCs. We found that SCH772984 abolished the growth of HHGMCs with or without Activin B (Figure 4A,B). However, neither SB202190 nor SP600125 inhibited HHGMCs proliferation induced by Activin B (Figure 4A,B). These data suggest that ERK signaling, but not JNK or P38, was involved in Activin B-induced cell proliferation in HHGMCs. These results were also supported by the CCK-8 assay (Figure 4C). We next investigated the effects of SCH772984 on hair shaft elongation using an organ culture model, and found that SCH772984 can block vibrissae growth induced by Activin B (Figure S2).

Elk1 is a major downstream cytosolic transcription factor of ERK signaling. We found that phosphorylation of Elk1 was significantly increased at $15 \mathrm{~min}$ after treatment with Activin B (Figure 4D,E). However, SCH772984 inhibited Activin B-induced phosphorylation of Elk1 (Figure 4F,G). These results indicate that $10 \mathrm{ng} / \mathrm{mL}$ Activin B promote the proliferation of HHGMCs through the ERK-Elk1 signaling pathway. 
A

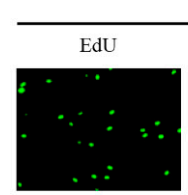

+ SB202190

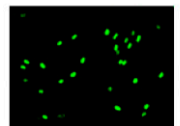

SP600125

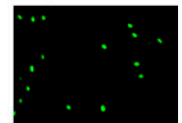

SCH772984
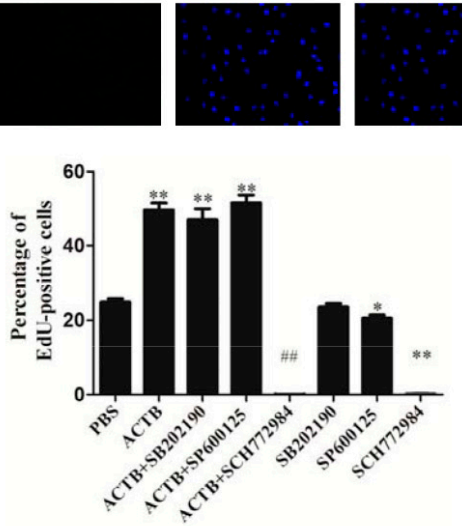

D

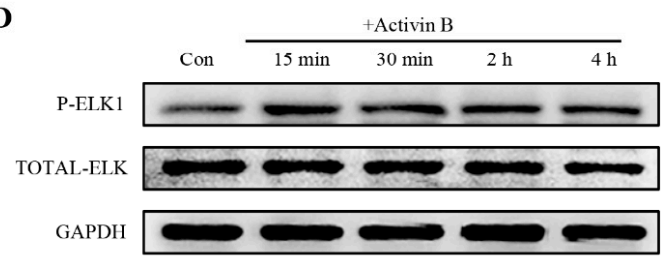

$\mathbf{E}$

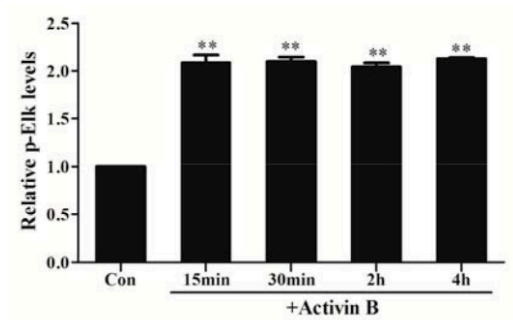

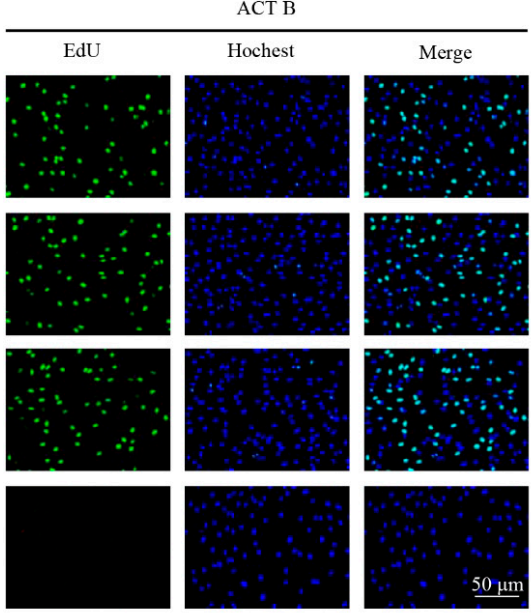

C

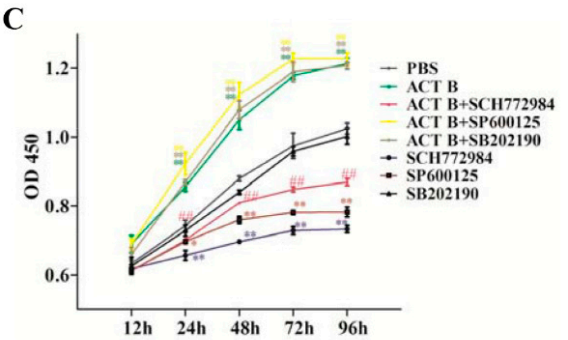

F Con $\quad$ ACT B $\quad$ ACT B+SCH772984

P-ELK1

TOTAL-ELK1

GAPDH

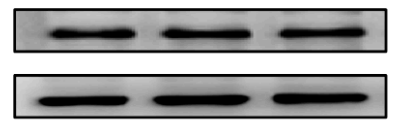

G

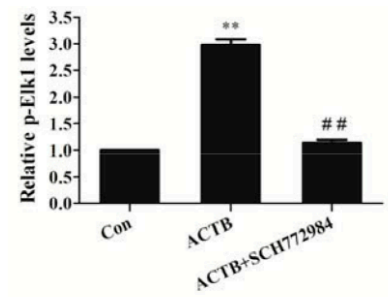

Figure 4. Activin B modulated the cell growth of HHGMCs through the ERK-Elk1 signaling pathway. (A) HHGMCs were serum starved for $24 \mathrm{~h}$ followed by treatment with SCH772984 (5 $\mu \mathrm{M})$, SP600125 $(5 \mu \mathrm{M})$, or SB202190 $(5 \mu \mathrm{M})$ for $2 \mathrm{~h}$. After treatment with PBS or $10 \mathrm{ng} / \mathrm{mL}$ Activin B for $48 \mathrm{~h}$, EdU staining (green fluorescence) was performed. Nuclei were counterstained with Hoechst 33342 (blue fluorescence). (B) The percentage of EdU-positive cells was calculated. (C) For the CCK-8 assay, HHGMCs were pretreated as (A) described. The CCK-8 assay was conducted at $12,24,48,72$, and $96 \mathrm{~h}$ after Activin B treatment. (D,E) The plot and the relative quantification of the expression of phosphorylation of Elk1 in HHGMCs treated with $10 \mathrm{ng} / \mathrm{mL}$ Activin B for $15 \mathrm{~min}, 30 \mathrm{~min}, 2 \mathrm{~h}$, or $4 \mathrm{~h}$. $(\mathrm{F}, \mathrm{G})$ The plot and the relative quantification of the expression of phosphorylation of Elk1 in the cells pretreated with SCH772984. ${ }^{*} p<0.05$; ${ }^{* *} p<0.01$, compared with the PBS group. ${ }^{\#} p<0.05$; ${ }^{\# \#} p<0.01$, compared with Activin B group. Three independent experiments were conducted per data point. All error bars indicate SEM. 
2.5. Activin B Accelerated the Cell Cycle Transition of HHGMCs from the G0/G1 Phase to the S Phase Through the ERK-Cyclin D1 Pathway

We then tested the role of Activin B in the regulation of the cell cycle in HHGMCs by flow cytometry. The results showed that Activin B significantly decreased the percentage of cells in the G0/G1 phase and increased the cell population in the $S$ phase (Figure 5A,B), which suggested that Activin B facilitated G1-S transition in the HHGMCs. However, the positive effect of Activin B on the cell cycle was blocked by ERK inhibitor SCH772984 (Figure 5A,B).

A
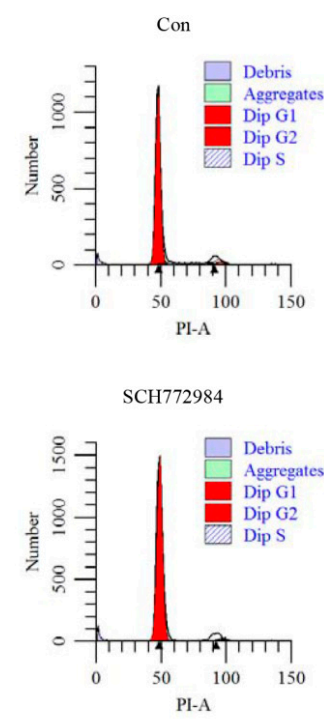

C

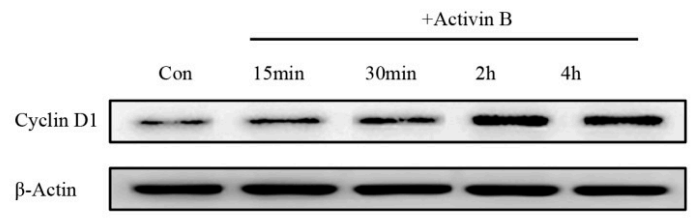

D

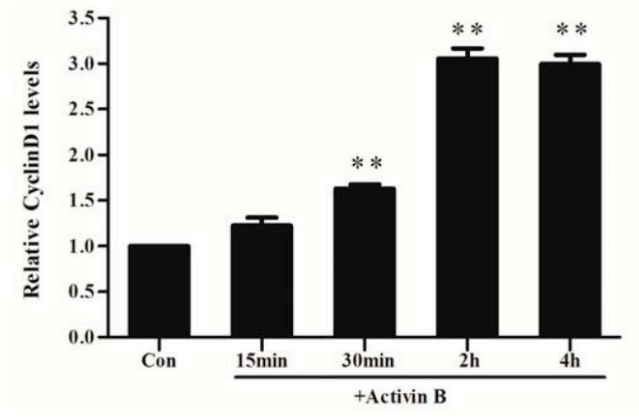

ACT B

ACT B+SCH772984
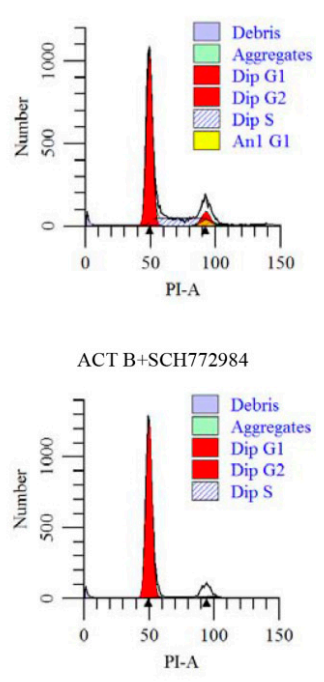

E

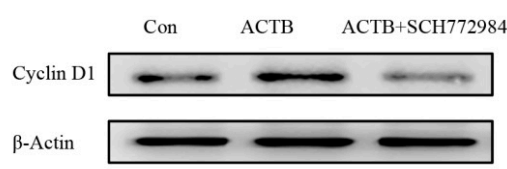

$\mathbf{F}$

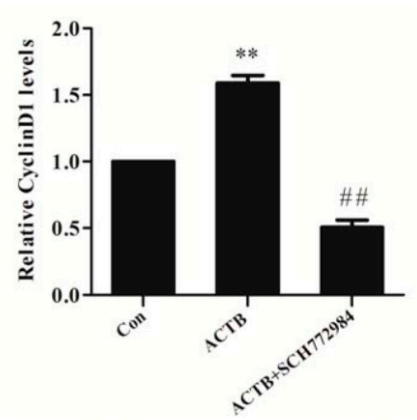

Figure 5. Activin B accelerated the cell cycle transition of HHGMCs from the G0/G1 phase to the $S$ phase through the ERK-Cyclin D1 pathway. (A) HHGMCs were serum starved for $24 \mathrm{~h}$ and pretreated with or without SCH772984 $(5 \mu \mathrm{M})$ for $2 \mathrm{~h}$. After treatment with $10 \mathrm{ng} / \mathrm{mL}$ Activin B or PBS for $48 \mathrm{~h}$, the cell cycle distribution was measured by flow cytometry using propidium iodide (PI) staining. (B) The percentages of cell cycle phase in G0/G1, S, and G2/M are shown in a bar graph form. (C,D) The plot and the relative quantification of the expression of Cyclin D1 in the cells treated with $10 \mathrm{ng} / \mathrm{mL}$ Activin B for $15 \mathrm{~min}, 30 \mathrm{~min}, 2 \mathrm{~h}$, and $4 \mathrm{~h}$. (E,F) The plot and the relative quantification of the expression of Cyclin D1 in the cells pretreated with SCH772984. ${ }^{*} p<0.05$; ${ }^{* *} p<0.01$, compared with the PBS group. ${ }^{\#} p<0.05$; ${ }^{\# \#} p<0.01$, compared with Activin B group. Three independent experiments were conducted per data point. All error bars indicate SEM. 
Cyclin D1 is a G1/S transition regulatory protein [31]. We found that the expression of Cyclin D1 was significantly increased by treatment with Activin B (Figure 5C,D). Furthermore, the upregulation of Cyclin D1 expression induced by Activin B was weakened by SCH772984 (Figure 5E,F). Taken together, these results indicate that $10 \mathrm{ng} / \mathrm{mL}$ Activin B promotes cell cycle progression from the G0/G1 phase to the $S$ phase through the ERK-Cyclin D1 signaling pathway.

\section{Discussion}

In postnatal life, HFs are periodically regenerated through a continuous cycle that includes the telogen, anagen, and catagen stages [32]. The onset of anagen in HFs recapitulates HF growth and development [33]. In this study, our results demonstrated that Activin B promotes vibrissae growth and accelerates mouse vibrissae anagen progression. This is consistent with the results of our previous study that Activin B promotes the hair cycle of mouse pelage HFs [14]. These data suggest that Activin $B$ plays a positive role in hair growth in different types of HFs. However, our finding is at odds with Jaenisch's finding [34]. Jaenisch and colleagues found that Activin $\beta B$ subunit gene disruption did not influence vibrissae HF development, suggesting that Activin B has little effect in vibrissae follicle development. However, Brown's study indirectly demonstrated the potential role of Activin B in vibrissae development [35]. Considering that the redundancy of activins may hamper the investigation of the physiological role of Activin B in vibrissae development in knockout mice studies, this may explain the discrepancy between Jaenisch's results and those of our study.

Normal HF growth depends on the activation of hair matrix cells [4]. We found that Activin $B$ significantly increased the proliferation of hair matrix cells in vivo and in vitro. Considering that hair matrix cells are highly proliferated in the anagen phase and play a part in the progression of the hair cycle [36], the positive effect of Activin B on hair matrix cell proliferation may count towards the vibrissae growth. Our finding is consistent with the report that recombinant human fibroblast growth factor-20 stimulated the proliferation of hair matrix cells and induced vibrissae follicle growth [37]. Han et al. also found that CsA is involved in mouse vibrissae growth through promoting hair matrix cell activation [38].

Determining the molecular mechanism that controls hair growth is of great importance in hair research. The MAPK pathway is an essential intracellular signal transduction pathway that regulates cell proliferation [39]. In the present study, our data showed that Activin B promotes hair matrix cell proliferation through the ERK-Elk1 pathway. Meldrum et al. reported that metalloproteinase is involved in UVB radiation-induced G1-S cell cycle progression in keratinocytes by the ERK/AKT/ CyclinD1 pathways [40]. Consistent with these findings, we showed that Activin B promotes G0/G1 to $S$ phase transformation through the ERK-Cyclin D1 pathway. In addition, we found that the levels of AKT phosphorylation were significantly increased $2 \mathrm{~h}$ after treatment with Activin B (Figure S3), suggesting that AKT may also be a downstream signal of ERK during Activin B-induced G1-S cell cycle progression of hair matrix cells. The previous study showed that cell cycle progression in the G1 phase has a key role in cell proliferation [41]. This gives a clue that Activin B may contribute to a growth-promoting effect on HFs, through regulating the cell cycle checkpoint protein Cyclin D1 by the ERK pathway.

In conclusion, our study demonstrated that $10 \mathrm{ng} / \mathrm{mL}$ Activin B accelerates vibrissae follicle growth in vitro in an organ culture model and in vivo in a mouse model. This is possibly mediated by enhancing hair matrix cell proliferation through the ERK-Elk1 signaling pathway and by accelerating hair matrix cell transition from the G0/G1 phase to the S phase through the ERK-Cyclin D1 pathway (Figure 6). Our findings may have clinical implications for hair loss treatment. 


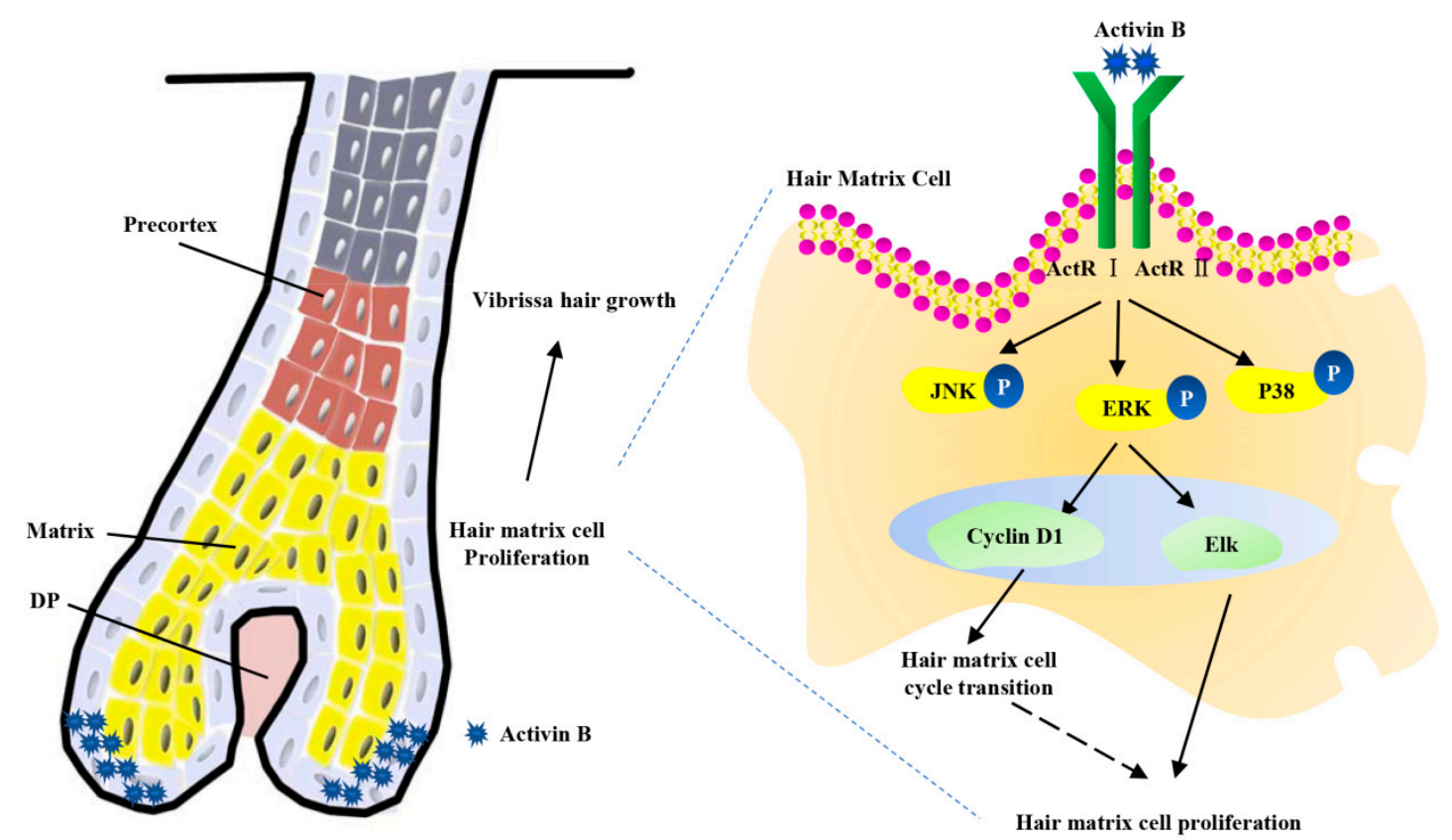

Figure 6. The proposed mechanisms model of Activin B on mouse vibrissae growth. Activin B accelerates vibrissae follicle growth. Activin B modulates the cell growth of hair matrix cells through the ERK-Elk1 signaling pathway and accelerates hair matrix cell transition from the G0/G1 phase to the $\mathrm{S}$ phase through the ERK-Cyclin D1 pathway.

\section{Materials and Methods}

\subsection{Mice}

Seven-week-old male C57BL/6 mice were purchased from the Southern Medical University Laboratory Animal Center. All animal procedures were approved by the Institutional Animal Care and Use Committee (IACUC) at Southern Medical University (L2018317).

\subsection{Anagen Induction Assay}

Paus' method was adapted to induce vibrissae follicle anagen by depilation [42]. C57BL/6 mice were anesthetized with an intraperitoneal injection of $2 \%$ pentobarbital sodium (Sigma, St. Louis, $\mathrm{MO}, \mathrm{USA} ; w / v ; 0.01 \mathrm{~mL} / \mathrm{g}$ body mass). The whisker pads of mice in the telogen phase, identified by the pink skin color, were depilated using a honey and wax mixture with clippers. After depilation, the mice were randomly divided into two groups of five mice each, and $10 \mathrm{ng}$ of Activin $\mathrm{B}$ in $1 \mathrm{~mL}$ of phosphate buffered solution (PBS) was administered on the whisker pads. A quantity of $1 \mathrm{ml}$ of PBS was used in the control groups. These treatments were applied to the whisker pads three times a day for 20 days. The skin over the vibrissae was observed and photographed every day. At the conclusion of the treatment, mice were sacrificed, and the whisker pads were carefully dissected and fixed in $4 \%$ paraformaldehyde.

\subsection{Histological Analysis}

The samples were dehydrated with a graded ethanol series and embedded in paraffin. Five-micrometer sections were cut for hematoxylin and eosin (H\&E) staining. H\&E staining was used to assess the hair cycle phase of the vibrissae follicles. For the quantitative evaluation of the anagen stage of hair follicles. Twenty longitudinal follicles per group were counted to calculate the hair cycle score as described in previous studies [30]. 


\subsection{Vibrissae Follicle Organ Culture}

An in vitro vibrissae culture system was established as described previously [43]. The whisker pads were cut from the mice, and the whole vibrissae follicles were dissected under a dissection microscope. Forty anagen vibrissae were collected from eight whisker pads from four mice. All isolated vibrissae follicles were randomly divided into two groups, with 20 vibrissae in each group. Vibrissae in the control group were cultured in the basal medium (Williams E medium (Gibco, Grand Island, NY, USA) containing $10 \mathrm{ng} / \mathrm{mL}$ hydrocortisone, $10 \mathrm{mg} / \mathrm{mL}$ insulin, $2 \mathrm{mM}$ L-glutamine, and $100 \mathrm{U} / \mathrm{mL}$ penicillin) at $37^{\circ} \mathrm{C}$ in a $5 \% \mathrm{CO}_{2}$ atmosphere. Vibrissae in the Activin $\mathrm{B}$ group were cultured in basal medium supplemented with $10 \mathrm{ng} / \mathrm{mL}$ Activin B. The medium was changed every other day. Pictures were taken on 1,3, 6, 9, and 12 days after culture. The elongation of the hair shaft was measured using Image-Pro Plus software (version 6.0, Media Cybernetics, Bethesda, MD, USA).

\subsection{Cell Culture}

Human hair germinal matrix cells (HHGMCs; Catalog\#2410) were purchased from ScienCell Research Laboratories (San Diego, CA, USA). The cells were cultured in a complete growth medium (mesenchymal stem cell medium (MSCM), supplemented with $5 \%$ fetal bovine serum (FBS), $1 \%$ stem cell growth supplement (MSCGS), and 1\% penicillin/streptomycin solution (P/S) (all from ScienCell, San Diego, CA, USA) and incubated at $37^{\circ} \mathrm{C}$ in a $5 \% \mathrm{CO}_{2}$ humidified atmosphere. The medium was changed every 1-2 days.

\subsection{The Inhibitor Treatment}

The cells were serum starved for $24 \mathrm{~h}$ and then incubated with ERK 1/2 inhibitor SCH772984 $(5 \mu \mathrm{M})$ (Selleck, Houston, TX, USA; Catalog\#S7101), P38 inhibitor SB202190 (5 $\mu \mathrm{M})$ (Selleck, Houston, TX, USA; Catalog\#S1077), or JNK inhibitor SP600125 (5 $\mu \mathrm{M})$ (Santa Cruz, Dallas, TX, USA; CAS 129-56-6) for $2 \mathrm{~h}$.

\subsection{Cell Proliferation Assays In Vivo}

After $10 \mathrm{ng} / \mathrm{mL}$ Activin B was applied to the depilated whisker pads for 10 days, EdU ( $5 \mathrm{mg} / \mathrm{kg}$ ) was intraperitoneally injected $4 \mathrm{~h}$ before the mice were sacrificed. The EdU staining was conducted using a Cell-Light ${ }^{\mathrm{TM}}$ Apollo567 Stain Kit (Ribobio, Shanghai, China; C10371-1) according to the manufacturer's protocol. Briefly, the sections of whisker pads were deparaffinized, rehydrated, and permeabilized. Then, the sections were incubated with an Apollo ${ }^{\circledR}$ fluorescent reaction cocktail for $30 \mathrm{~min}$. After washing, the sections were counterstained with Hoechst 33342 (1:100; Ribobio, Shanghai, China; C00033) and examined using a confocal fluorescence microscope (LSM 880; Carl Zeiss, Jena, Germany).

\subsection{Cell Proliferation Assays In Vitro}

Cell proliferation of HHGMCs was detected by Cell Counting Kit-8 (CCK-8) assay and EdU incorporation assay.

The CCK-8 (Bimake, Houston, TX, USA; B34304) assay was performed according to the manufacturer's instructions. The cells at a concentration of $5 \times 10^{3}$ per well were seeded into 96-well culture plates in $100 \mu \mathrm{L}$ complete growth medium. The cells were then serum-starved for $24 \mathrm{~h}$. Activin $\mathrm{B}$ at different concentrations $(5,10,20,40,80,160 \mathrm{ng} / \mathrm{mL})$ was added to each well $(n=5$ for each concentration). At $12,24,48,72$, and $96 \mathrm{~h}$ after treatment, $10 \mu \mathrm{L} \mathrm{CCK}-8$ was added to each well and incubated for $2 \mathrm{~h}$ at $37^{\circ} \mathrm{C}$. The absorbance at $450 \mathrm{~nm}$ was measured by using an Epoch Microplate Spectrophotometer (BioTek, Winooski, VT, USA).

The EdU incorporation assay was carried out using the Cell-Light EdU Apollo488 in vitro kit (Ribobio, Shanghai, China; C10310-3) according to the manufacturer's instructions. The HHGMCs were seeded in 48-well plates at a density of $10^{4}$ cells per well and treated with PBS or $10 \mathrm{ng} / \mathrm{mL}$ 
Activin B for $48 \mathrm{~h}$. Then the cells were incubated with $50 \mu \mathrm{M}$ EdU for $2 \mathrm{~h}$. Following fixation with $4 \%$ paraformaldehyde and permeabilization in $0.5 \%$ Triton X-100, the cells were stained with Apollo ${ }^{\circledR}$ fluorescent dye. After washing with PBS, the cells were counterstained with Hoechst 33342 . The EdU-positive nuclei were determined under a fluorescence microscope. The number of positive cells was counted manually in ten fields-of-view randomly selected from each well. The percentage of positive cells was calculated.

\subsection{Cell Cycle Analysis}

For cell cycle analysis, about $1 \times 10^{6}$ treated or untreated HHGMCs were collected and fixed with $80 \%$ ice-cold ethanol for $2 \mathrm{~h}$ at $4{ }^{\circ} \mathrm{C}$. After washing and centrifugation, $0.5 \mathrm{~mL}$ PI/RNase (BD Pharmingen, San Diego, CA, USA) was added to the cell lysis and incubated at room temperature for $15 \mathrm{~min}$ in the dark. The samples were then analyzed by LSRFortessa ${ }^{\mathrm{TM}} \mathrm{X}-20$ flow cytometry (BD Pharmingen, San Diego, CA, USA). The flow cytometry data were analyzed using ModFit LT 5.0 software (Verity Software House, Topsham, ME, USA).

\subsection{Western Blot Analysis}

The HHGMCs were serum-starved for $24 \mathrm{~h}$ and cultured in control medium with or without $10 \mathrm{ng} / \mathrm{mL}$ Activin B. At $15 \mathrm{~min}, 30 \mathrm{~min}, 2 \mathrm{~h}$, or $4 \mathrm{~h}$ after treatment, the cells were washed with ice-cold PBS, lysed by radioimmnoprecipitation assay (RIPA) lysis buffer (KeyGEN, Jiangsu, China), and collected by centrifugation at $14,000 \mathrm{rpm}$ at $4{ }^{\circ} \mathrm{C}$ for $10 \mathrm{~min}$. The protein concentration was determined using a bicinchoninic acid (BCA) Protein Assay Kit (Beyotime Technology, Shanghai, China; P0010).

Equal amounts of protein samples from different groups were separated by sodium dodecyl sulfate-polyacrylamide gel electrophoresis (SDS-PAGE) and then transferred to a polyvinylidene fluoride membrane (Millipore, Bedford, MA, USA). The membranes were blocked with QuickBlock ${ }^{\mathrm{TM}}$ Blocking Buffer (Beyotime, Shanghai, China; P0252) for $1 \mathrm{~h}$ at room temperature and then incubated with a primary antibody against p-JNK(1:1000; Cell Signaling, Danvers, MA, USA; \#4668T), p-ERK(1:1000; Cell Signaling, Danvers, MA, USA; \#4370S), p-P38(1:1000; Cell Signaling, Danvers, MA, USA; \#4511S), p-Elk1(1:1000; Santa Cruz, Dallas, TX, USA; sc-135646), or Cyclin D1 (1:1000; Cell Signaling, Danvers, MA, USA; \#2922S) overnight at $4{ }^{\circ} \mathrm{C}$. After being washed with Tris-buffered saline containing Tween-20 (TBST), the membranes were incubated with the corresponding horseradish peroxidase (HRP)-conjugated secondary antibody (1:2000; Cwbio, Beijing, China; CW0156S) for $1 \mathrm{~h}$ at room temperature. The membranes were washed and exposed using the enhanced chemiluminescent substrate (ECL) (Millipore, Bedford, MA, USA). The blots were then washed with stripping buffer (Millipore, Bedford, MA, USA) for $10 \mathrm{~min}$ at room temperature and re-probed with antibodies against total-JNK (1:1000; Cell Signaling, Danvers, MA, USA; \#9258), total-ERK (1:1000; Cell Signaling, Danvers, MA, USA; \#4695S), total-P38 (1:1000; Cell Signaling, Danvers, MA, USA; \#9212S), or total-Elk1 (1:1000; Santa Cruz, Dallas, TX, USA; sc-65986). Then, the intensity of the band was quantified using Quantity One software (Bio-Rad, Hercules, CA, USA).

\subsection{Statistical Analysis}

Statistical analysis was performed using SPSS13.0 software (SPSS Inc., Chicago, IL, USA). Data are expressed as mean \pm standard errors of the mean (SEM). The results were compared using an independent samples $t$-test. A value of $p<0.05$ was considered statistically significant.

Supplementary Materials: Supplementary materials can be found at http:/ /www.mdpi.com/1422-0067/20/4/ $853 /$ s1.

Author Contributions: P.T., design and collection of data, data analysis and interpretation, and article writing; X.W., design and collection of data, data analysis and interpretation, and article writing; S.H., collection of data; C.L. and Y.D., data analysis and interpretation; M.Z. and F.Y., provision of administrative support; L.Z. (Lu Zhang), 
conception and design, financial support, and final approval of the article; L.Z. (Lin Zhang), conception and design, financial support, article writing, and final approval of the article.

Acknowledgments: This work is supported by the National Natural Science Foundation of China (81872514, 81571860, 81430045, 81703147, 81402613) and the Colleges Pearl River Scholar Funded Scheme (GDUPS2013, GDUPS2015). The project is also supported by the Natural Science Foundation of Guangdong Province (2014A030312013, 2017A030310292) and the Chinese Postdoctoral Science Foundation (2018M630966). Lu Zhang and Lin Zhang would also like to thank the Program for Changjiang Scholars and Innovative Research Team in University (IRT 16R37) for their support.

Conflicts of Interest: The authors indicate no potential conflicts of interest.

\section{Abbreviations}

$\begin{array}{ll}\text { EdU } & \text { 5-ethynyl-2' }{ }^{\prime} \text { deoxyuridine } \\ \text { CCK-8 } & \text { Cell Counting Kit-8 } \\ \text { HF } & \text { Hair follicle } \\ \text { ORS } & \text { Outer root sheath } \\ \text { IRS } & \text { Inner root sheath } \\ \text { DP } & \text { Dermal papilla } \\ \text { HE } & \text { Hematoxylin and eosin } \\ \text { TGF- } \beta & \text { Transforming growth factor - } \beta \\ \text { MAPK } & \text { Mitogen-activated protein kinase } \\ \text { EGF } & \text { Epidermal growth factor } \\ \text { ACT B } & \text { Activin B } \\ \text { HHGMCs } & \text { Human hair germinal matrix cell } \\ \text { PBS } & \text { Phosphate buffer solution } \\ \text { PI } & \text { Propidium iodide } \\ \text { RIPA } & \text { Radioimmnoprecipitation assay } \\ \text { BCA } & \text { Bicinchoninic acid } \\ \text { SDS-PAGE } & \text { Sodium dodecyl sulfate-polyacrylamide gel electrophoresis } \\ \text { TBST } & \text { Tris-buffered saline containing Tween-20 } \\ \text { HRP } & \text { Horseradish peroxidase } \\ \text { ECL } & \text { Enhanced chemiluminescent }\end{array}$

\section{References}

1. Schneider, M.R.; Schmidt-Ullrich, R.; Paus, R. The hair follicle as a dynamic miniorgan. Curr. Biol. 2009, 19, 132-142. [CrossRef] [PubMed]

2. Davidson, P.; Hardy, M.H. The development of mouse vibrissae in vivo and in vitro. J. Anat. 1952, 86, 342-356. [PubMed]

3. Philpott, M.P.; Kealey, T. Cyclical changes in rat vibrissa follicles maintained in vitro. J. Investig. Dermatol. 2000, 115, 1152-1155. [CrossRef] [PubMed]

4. Paus, R.; Cotsarelis, G. The biology of hair follicles. N. Engl. J. Med. 1999, 341, 491-497. [CrossRef] [PubMed]

5. Stenn, K.S.; Paus, R. Controls of hair follicle cycling. Physiol. Rev. 2001, 81, 449-494. [CrossRef] [PubMed]

6. Rishikaysh, P.; Dev, K.; Diaz, D.; Qureshi, W.M.; Filip, S.; Mokry, J. Signaling involved in hair follicle morphogenesis and development. Int. J. Mol. Sci. 2014, 15, 1647-1670. [CrossRef] [PubMed]

7. Chen, W.; Ten Dijke, P. Immunoregulation by members of the TGF $\beta$ superfamily. Nat. Rev. Immunol. 2016, 16, 723-740. [CrossRef]

8. Xia, Y.; Schneyer, A.L. The biology of activin: Recent advances in structure, regulation and function. J. Endocrinol. 2009, 202, 1-12. [CrossRef]

9. Pangas, S.A.; Woodruff, T.K. Activin signal transduction pathways. Trends. Endocrinol. Metab. 2000, 11, 309-314. [CrossRef]

10. McDowall, M.; Edwards, N.M.; Jahoda, C.A.; Hynd, P.I. The role of activins and follistatins in skin and hair follicle development and function. Cytokine Growth Factor Rev. 2008, 19, 415-426. [CrossRef] 
11. Nakamura, M.; Matzuk, M.M.; Gerstmayer, B.; Bosio, A.; Lauster, R.; Miyachi, Y. Control of pelage hair follicle development and cycling by complex interactions between follistatin and activin. FASEB J. 2003, 17, 497-499. [CrossRef] [PubMed]

12. Jhaveri, S.; Erzurumlu, R.S.; Chiaia, N.; Kumar, T.R.; Matzuk, M.M. Defective whisker follicles and altered brainstem patterns in activin and follistatin knockout mice. Mol. Cell. Neurosci. 1998, 12, 206-219. [CrossRef] [PubMed]

13. Seo, C.H.; Kwack, M.H.; Kim, M.K.; Kim, J.C.; Sung, Y.K. Activin A-induced signalling controls hair follicle neogenesis. Exp. Dermatol. 2017, 26, 108-115. [CrossRef] [PubMed]

14. Jia, Q.; Zhang, M.; Kong, Y.; Chen, S.; Chen, Y.; Wang, X. Activin B promotes initiation and development of hair follicles in mice. Cells Tissues Organs. 2013, 198, 318-326. [CrossRef] [PubMed]

15. Zhang, M.; Liu, N.Y.; Wang, X.E.; Chen, Y.H.; Li, Q.L. Activin B promotes epithelial wound healing in vivo through RhoA-JNK signaling pathway. PLoS ONE 2011, 6, e25143. [CrossRef]

16. Hardy, M.H. The secret life of the hair follicle. Trends Genet. 1992, 8, 55-61.

17. Blanpain, C.; Fuchs, E. Epidermal homeostasis: A balancing act of stem cells in the skin. Nat. Rev. Mol. Cell Biol. 2009, 10, 207-217. [CrossRef]

18. Geyfman, M.; Plikus, M.V.; Treffeisen, E.; Andersen, B.; Paus, R. Resting no more: Re-defining telogen, the maintenance stage of the hair growth cycle. Biol. Rev. Camb. Philos. Soc. 2015, 90, 1179-1196. [CrossRef]

19. Kwack, M.H.; Ahn, J.S.; Kim, M.K.; Kim, J.C.; Sung, Y.K. Dihydrotestosterone-inducible IL-6 inhibits elongation of human hair shafts by suppressing matrix cell proliferation and promotes regression of hair follicles in mice. J. Investig. Dermatol. 2012, 132, 43-49. [CrossRef]

20. Zhu, H.L.; Gao, Y.H.; Yang, J.Q.; Li, J.B.; Gao, J. Serenoa repens extracts promote hair regeneration and repair of hair loss mouse models by activating TGF- $\beta$ and mitochondrial signaling pathway. Eur. Rev. Med. Pharmacol. Sci. 2018, 22, 4000-4008.

21. Derynck, R.; Zhang, Y.E. Smad-dependent and Smad-independent pathways in TGF- $\beta$ family signaling. Nature 2003, 425, 577-584. [CrossRef] [PubMed]

22. Yue, J.; Mulder, K.M. Activation of the Mitogen-Activated Protein Kinase Pathway by TGF $\beta$. Methods Mol. Biol. 2000, 142, 125-131. [PubMed]

23. Zhang, L.; Xu, P.; Wang, X.; Zhang, M.; Yan, Y.; Chen, Y. Activin B regulates adipose-derived mesenchymal stem cells to promote skin wound healing via activation of the MAPK signaling pathway. Int. J. Biochem. Cell Biol. 2017, 87, 69-76. [CrossRef] [PubMed]

24. Sohn, K.M.; Jeong, K.H.; Kim, J.E.; Park, Y.M.; Kang, H. Hair growth-promotion effects of different alternating current parameter settings are mediated by the activation of Wnt/beta-catenin and MAPK pathway. Exp. Dermatol. 2015, 24, 958-963. [CrossRef] [PubMed]

25. Hibino, T.; Nishiyama, T. Role of TGF- $\beta 2$ in the human hair cycle. J. Dermatol. Sci. 2004, 35, 9-18. [CrossRef] [PubMed]

26. Bai, T.; Liu, F.; Zou, F.; Zhao, G.; Jiang, Y.; Liu, L. Epidermal Growth Factor Induces Proliferation of Hair Follicle-Derived Mesenchymal Stem Cells Through Epidermal Growth Factor Receptor-Mediated Activation of ERK and AKT Signaling Pathways Associated with Upregulation of Cyclin D1 and Downregulation of p16. Stem. Cells Dev. 2017, 26, 113-122. [CrossRef]

27. Slominski, A.; Paus, R. Melanogenesis is coupled to murine anagen: Toward new concepts for the role of melanocytes and the regulation of melanogenesis in hair growth. J. Investig. Dermatol. 1993, 101, 90s-97s. [CrossRef]

28. Slominski, A.; Paus, R.; Costantino, R. Differential expression and activity of melanogenesis-related proteins during induced hair growth in mice. J. Investig. Dermatol. 1991, 96, 172-179. [CrossRef]

29. Slominski, A.; Paus, R.; Plonka, P.; Chakraborty, A.; Maurer, M.; Pruski, D. Melanogenesis during the anagen-catagen-telogen transformation of the murine hair cycle. J. Investig. Dermatol. 1994, 102, 862-869. [CrossRef]

30. Muller-Rover, S.; Handjiski, B.; van der Veen, C.; Eichmuller, S.; Foitzik, K.; McKay, I.A. A comprehensive guide for the accurate classification of murine hair follicles in distinct hair cycle stages. J. Investig. Dermatol. 2001, 117, 3-15. [CrossRef]

31. Hengstschlager, M.; Braun, K.; Soucek, T.; Miloloza, A.; Hengstschlager-Ottnad, E. Cyclin-dependent kinases at the G1-S transition of the mammalian cell cycle. Mutat. Res. 1999, 436, 1-9. [CrossRef] 
32. Krause, K.; Foitzik, K. Biology of the hair follicle: The basics. Semin. Cutan. Med. Surg. 2006, 25, 2-10. [CrossRef] [PubMed]

33. Alonso, L.; Fuchs, E. The hair cycle. J. Cell Sci. 2006, 119, 391-393. [CrossRef]

34. Vassalli, A.; Matzuk, M.M.; Gardner, H.A.; Lee, K.F.; Jaenisch, R. Activin/inhibin beta B subunit gene disruption leads to defects in eyelid development and female reproduction. Genes. Dev. 1994, 8, 414-427. [CrossRef]

35. Brown, C.W.; Houston-Hawkins, D.E.; Woodruff, T.K.; Matzuk, M.M. Insertion of Inhbb into the Inhba locus rescues the Inhba-null phenotype and reveals new activin functions. Nat. Genet. 2000, 25, 453-457. [CrossRef] [PubMed]

36. Legue, E.; Nicolas, J.F. Hair follicle renewal: Organization of stem cells in the matrix and the role of stereotyped lineages and behaviors. Development 2005, 132, 4143-4154. [CrossRef] [PubMed]

37. Xu, X.G.; Gong, L.; Jiang, T.L.; Li, Y.H.; Gao, X.H.; Tian, H. Stimulation of mouse vibrissal follicle growth by recombinant human fibroblast growth factor 20. Biotechnol. Lett. 2018, 40, 1009-1014. [CrossRef] [PubMed]

38. Xu, W.; Fan, W.; Yao, K. Cyclosporine A stimulated hair growth from mouse vibrissae follicles in an organ culture model. J. Biomed. Res. 2012, 26, 372-380. [CrossRef]

39. Johnson, G.L.; Lapadat, R. Mitogen-activated protein kinase pathways mediated by ERK, JNK, and p38 protein kinases. Science 2002, 298, 1911-1912. [CrossRef]

40. Han, W.; He, Y.Y. Requirement for metalloproteinase-dependent ERK and AKT activation in UVB-induced G1-S cell cycle progression of human keratinocytes. Photochem. Photobiol. 2009, 85, 997-1003. [CrossRef]

41. Bose, C.; Udupa, K.B. Erythropoietin enhancement of rat pancreatic tumor cell proliferation requires the activation of ERK and JNK signals. Am. J. Physiol. Cell Physiol. 2008, 295, 394-405. [CrossRef] [PubMed]

42. Paus, R.; Stenn, K.S.; Link, R.E. Telogen skin contains an inhibitor of hair growth. Br. J. Dermatol. 1990, 122, 777-784. [CrossRef] [PubMed]

43. Lee, J.; Wu, W.; Kopan, R. Murine vibrissae cultured in serum-free medium reinitiate anagen. J. Investig. Dermatol. 2008, 128, 482-485. [CrossRef] [PubMed] 